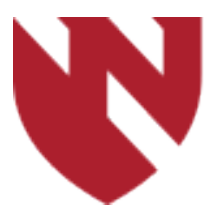

\title{
The Uncharted Waters of Graduate Medical Education During a Pandemic
}

Chandrakanth Are

University of Nebraska Medical Center

Tell us how you used this information in this short survey.

Follow this and additional works at: https://digitalcommons.unmc.edu/gmerj

Part of the Higher Education Commons, and the Medicine and Health Sciences Commons

\section{Recommended Citation}

Are, C. The Uncharted Waters of Graduate Medical Education During a Pandemic. Graduate Medical Education Research Journal. 2020 Dec 09; 2(2).

https://digitalcommons.unmc.edu/gmerj/vol2/iss2/1

This Editorial is brought to you for free and open access by DigitalCommons@UNMC. It has been accepted for inclusion in Graduate Medical Education Research Journal by an authorized editor of DigitalCommons@UNMC. For more information, please contact digitalcommons@unmc.edu. 


\section{The Uncharted Waters of Graduate Medical Education During a Pandemic}

\section{Keywords}

graduate medical education pandemic

Creative Commons License

(c) $($ i) $(9)$

This work is licensed under a Creative Commons Attribution-Noncommercial-No Derivative Works 4.0 License. 


\section{The Unchartered Waters of Graduate Medical Education During a Pandemic}

Chandrakanth Are, MBBS, MBA, FRCS, FACS

University of Nebraska Medical Center, Division of Surgical Oncology, Department of Surgery

There have been a handful of seminal events in the past century or so that influenced medical education in a dramatic fashion. The Flexner report at the beginning of the 20th century was a major transformative milestone and promulgated new standards for medical education. ${ }^{1}$ Establishing the residency system of training by Dr. William Stewart Halsted was another major milestone. This concept of residency was extremely popular and was approved by the American Medical Association (AMA) House of Delegates in 1928 as the model for approving hospitalbased residencies in specialties. ${ }^{2}$ These events were the result of voluntarily initiated attempts, by the medical fraternity, to improve medical education and create educational platforms that mostly have stood the test of time.

In contrast, some other cataclysmic events of the past century were disruptive for medical education. These events were not called for but nonetheless had a drastic impact on medical education. The assassination of Archduke Franz Ferdinand of the AustriaHungary empire in 1914 by a Serbian triggered World War I, which contributed to the earliest large-scale disruption of medical education of the 20th century. ${ }^{3,4}$ It is ironic that this interruption in education was the result of two shots fired by an 18-yearold student. This was at a time when the streamlining and transformation of medical education based on the Flenxer report was barely getting started. The declaration of the First World War in August 1914 not only heralded an interruption of medical education but also created many professional and ethical dilemmas for medical students. Young medical students were caught between Scylla and Charybdis, uncertain about whether to volunteer and display patriotism or to stay behind and continue their education with the risk of being shamed. ${ }^{5}$

Right on the heels of the First World War came the 1918 influenza pandemic. This pandemic infected 500 million people and claimed almost 50 million lives worldwide. ${ }^{6}$ The pandemic was responsible for 675,000 deaths in the U.S. ${ }^{6}$ Medical education was interrupted as students were either ill themselves or called upon to take care of patients or their own peers. ${ }^{7}$ World War II led to another large-scale disruption of medical education, with the introduction of the three- year accredited medical curriculum to address the physician shortages. ${ }^{8}$

Graduate Medical Education (GME) was yet to be molded into the completely formal hospital-based residency model on a large scale. It was not until the later part of the 1940's that GME materialized into the formal hospital-based residency model of training. As a result, during these events most physicians continued their work/training in the apprentice model prevalent at that time with interruptions due to deployment or re-distribution of workforce. Although there were subsequent wars, fortunately none of those had a largescale major impact on medical education unlike the prior events.

Here we are now almost a century to date, going through another major disruption of medical education due to COVID-19. ${ }^{9}$ Similar to other events of the 20th century, the pandemic has disrupted medical education on a major scale. ${ }^{10}$ The pandemic has had an adverse effect on GME at various levels ranging from: cancellation of elective procedures and educational activities, increased clinical burden or taking care of patients beyond their specialty, shifting from in-person to online didactics, cancellation of skills training, inability to meet stipulated educational requirements, changing to virtual interviews and newer training in personal protective equipment (PPE). The pandemic has also had a major impact on well-being of the house officers due to various reasons ranging from: sense of uncertainty, fear of contracting COVID-19, capacity issues with testing for COVID-19, unprecedented clinical volume of work, disruption of normal work patterns, lack of peer interactions and delay or unavailability of counseling services.

There is probably no adult with a living memory of the 1918 pandemic to provide guidance on how to handle the current pandemic effectively. Similarly, there is probably no one with any experience of how to steer the GME world during a pandemic. Most of the prior events had a greater impact on undergraduate medical education as GME was still being molded into the structure that we know of now. This is probably the first major disruption of modern day GME. It is likely that many of the GME changes instituted to address the pandemic will revert back to normal. It is also quite likely that some of these changes, beneficial or not may become permanent.

It behooves us to not only address the immediate challenges but also to use this as an opportunity to bring about some of the muchdesired changes to GME. Several aspects of GME albeit functioning well could benefit from a dose of change. The prime example is the shift from time-construct based training to competency-based training. As a result of the pandemic, our accrediting bodies have permitted graduation of residents even if they did not meet the minimum requirements, as long as they are deemed competent by the Clinical Competency Committee (CCC). ${ }^{11}$ Could this microbially-forced accidental change be the harbinger of a more substantive change to our training model, where a resident can graduate upon demonstrating competency rather than reaching a set time-point in their training?

The current process of applying for an interview has become very expensive with many declining interviews due to financial difficulty For example, Jiang et al noted that an applicant spent an average of $\$ 6,000$ for the 2019 urology interview cycle. ${ }^{12}$ As a result of the pandemic, interviews for the 2021 cycle have migrated entirely to virtual platforms. This has been perceived by many to be far inferior to the traditional in-person interview. At the same time, the virtual interview may allow the applicants to save some costs by eliminating travel expenses. It may be likely that the future process will combine the benefits of both in-person and virtual platforms to maximize the interview opportunities for the applicants while reducing costs.

Telehealth is seeing its moment of glory. Telehealth can help to address issues relating to physician shortages by providing care on digital platforms even in remote locations. Could it also help to address disparities in health care delivery when combined with universal availability of adequate technological platforms? Similarly, could the virtual platforms increase the reach of medical education to areas that hitherto lacked access to good quality graduate medical education? The current pandemic may also become a major factor in choosing a specialty. Is it likely that we will see a rise of interest 
in infectious diseases and other related specialties.

Through all of this, we in the GME world should continue to ensure that our focus on the approximately 145,000 house officers in GME programs across the nation does not waver. The stressors of this continuously evolving situation combined with the fear of uncertainty can sometimes relegate GME issues to the back seat. This mistake can prove costly as these 145,000 house officers in training are not only toiling away in the frontlines now but are also the future of our profession, which is vital to addressing this pandemic and any other calamities in the future.

House officers are one of the few professionals that are routinely scheduled to work up to 80 hours per week for years on end. House officers also occupy a unique position in the ladder of professional hierarchies. They are learners but not medical students. They are physicians but not faculty. As a result, house officers tend to be fulltime learners and employees at the same time, which neither offers them the lenience of a student nor the liberties of a faculty. Consequently, house officers harbor little free will to determine their work patterns and are usually in the first line of defense when emergencies such as this pandemic befall on us.

The present house officers are the first batch of Gen-C (Generation COVID-19) residents and fellows. The Gen-C house officers are receiving their training in such unique circumstances that no one in the GME world has any knowledge or experience of. At the same time, our house officers across the nation, along with faculty and other health care professionals, have risen to the occasion. Despite any number of known or unknown professional or personal stressors, the majority of them have kept a brave face and showed up to work to do what they do best to take care of patients in the most stressful of times even at risk to their own lives.

During the last pandemic in 1918, the Harvard hospital's board trustees wrote in that year's annual report.?

"Too much cannot be said for the heroism of our physicians and nurses who, despite depleted numbers owing to the war, worked under conditions beyond description"
Likewise, too much cannot be said of our house officers, faculty and all of our other health professions that are working under the most unusually stressful conditions with likely no end in the immediate near sight. The 1918 pandemic revolutionized medicine in many ways. So, will this pandemic as long as we take good care of our health care professionals who will be the drivers of those changes and in turn save our nation.

https://doi.org/10.32873/unmc.dc.gmerj.2.2.001

\section{References}

1 Duffy TP, The Flexner Report-100 years later. Yale J Biol Med. 2011;84: 269-276

2 Council on Medical Education, Hospitals of the American Medical Association. Essentials in a hospital approved for residencies in specialties. JAMA 1933;100: 899-910

3 https://www.nytimes.com/interactive/projects/cp/ obituaries/archives/archduke-franz-ferdinand-worldwar

4 https://www.doe.in.gov/sites/default/files/standards/ guide.pdf

5 Crofton L. Medical students in the first world war: The Edinburgh experience. Proc. R. Coll. Physicians Edinb.1997;27: 227-241

6 https://www.cdc.gov/flu/pandemic-resources/1918pandemic-h1n1.html

7 https://hms.harvard.edu/magazine/pandemic/gripdisease

8 Schwartz CC, Ajjarapu AS, Stamy CD et al. Comprehensive review of 3-year and accelerated medical school programs: a century in review. Med Educ Online. 2018;23: 1530557

9 https://coronavirus.jhu.edu/map.html

10 Rana T, Hackett C, Quezada T et al. Medicine and surgery residents' perspectives on the impact of COVID-19 on graduate medical education. Med Education Online. 25:1, 1818439, DOI:10.1080/10872 981.2020 .1818439

11 https:/www.abms.org/news-events/abms-statement-todios-regarding-coronavirus-disease-2019-covid-19/

12 Jiang, J., Engelsgjerd, J. S., LaGrange, C. A., , Deibert, C. M. The Financial Burden of the Urology Match: Room for improvement. Graduate Medical Education Research Journal. 2019 Dec 13; 1(1). https:// digitalcommons.unmc.edu/gmerj/vol1/iss1/8 